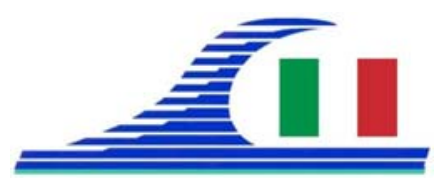

Conférence Méditerranéenne Côtière et Maritime EDITION 3, FERRARA, ITALIA (2015)

Coastal and Maritime Mediterranean Conference

Disponible en ligne - http://www.paralia.fr - Available online

\title{
Dredged sediments treatment by electrokinetics
}

\author{
Yue SONG $^{1}$, Ahmed BENAMAR ${ }^{1}$, Mohamed AMMAMI ${ }^{1}$ \\ 1. LOMC UMR 6294 CNRS-Université du Havre, 76600 Le Havre, France. \\ yue.song@univ-lehavre.fr ; ahmed.benamar@univ-lehavre.fr
}

\begin{abstract}
:
Dredging practices constitute a challenge for developing and maintaining harbor and fluvial activities because of the bound pollutants as heavy metals, PAHs, etc. Dewatering processes is of important consideration in reuse of sediments by easy maneuverability and low cost transport. A low cost method as mechanical compaction is the more used to reduce the water content than the other technologies like freeze-thaw, centrifuge force etc. (YUAN \& WENG, 2003; TUAN \& SILLANPAA, 2010). Sludge dewatering by electrokinetic process effect is a promising technology when processing time and potential gradient are controlled. An experimental study coupling electrokinetic and mechanical loading was carried out in laboratory using harbor dredged sediments. It has been demonstrated that an electro-dewatering (EDW) process is a cost-effective remediation technology when combined with mechanical dewatering (MDW). The influence of electric field intensity and mechanical load on the consolidation and water removal efficiency was assessed. In general, more water removal efficiency needs more energy consumption and higher compression level. In addition to EDW, contaminants can be extracted using a quite high potential gradient.
\end{abstract}

Keywords: Dredged sediments, Electrokinetic, Dewatering, Mechanical consolidation

\section{Introduction}

Usually the dredged sediments were treated by marine deposit because of the weak requirements. However, this operation cannot be systematically considered owing to the likely high level of contamination of such materials in recent years. Nevertheless, high cost of the land and management must be considered. In order to minimize the volume occupied by the large amount of wet material, dewatering operation is necessary. It has been demonstrated that electro-dewatering (EDW) is a cost-effective remediation technology assisted by mechanical dewatering (MDW) (MAHMOUD et al., 2011). In electro-osmotic dewatering, the moisture content of a solid-liquid mixture remains unchanged at the drainage surface (electrode area), while it decreases drastically near the opposite electrode (IWATA et al., 2007). On the other hand, beside of the electroosmotic process, electric field applied on sludge produces Electrophoresis and Electromigration, improving contaminants transport. Hence, dewatering and decontamination are two advantages of using the EDW method. This paper reports the results of a laboratory study on EDW of dredged sediments, assisted with mechanical 
Côtes méditerranéennes menacées :

Risques et défis dans le contexte du changement climatique

consolidation. The efficiency of EDW is addressed and compared to MDW alone, and it was showed that coupling two processes leads to a best efficiency.

\section{Materials and methods}

The sediments were dredged from the waterway of Tancarville channel (France); and the sample of $40 \mathrm{~kg}$ collected by a shovel was stored at $4^{\circ} \mathrm{C}$. Used material is mainly silt (87\%) with a low fraction of clay (6\%) and its grain size extends up to $500 \mu \mathrm{m}$. It presents a $\mathrm{pH}$ and an electrical conductivity close respectively to 8.4 and $1.6 \mathrm{~ms} / \mathrm{cm}$. The measured water content of the sediment at storage was about $93 \%$.

The experimental setup (Figure1) consists of a U-PVC cylindrical cell (diameter of $90 \mathrm{~mm}$, length of $205 \mathrm{~mm}$ ), a DC power supply, graphite electrodes and a load device. The cell was positioned vertically under the load device and the two electrodes were placed at the ends of the sample, allowing drainage. A filter $(0.45 \mu \mathrm{m})$ is placed between the cathode-perforated plate and the sample. After each test, which takes 48 hours, the sample was cut as many slices and moisture content, $\mathrm{pH}$ and electrical conductivity were measured within each layer. The effluent was also analyzed for electro-remediation consideration, and the contaminant concentrations measured. The first test without EK dewatering, serves as a reference to the other 12 tests in this investigation. Four loading values and three electrical potential values were combined to achieve the tests. The DC power supply ranged from 0.5 to $1.5 \mathrm{~V} / \mathrm{cm}$ and the mechanical load ranged from 25 to $200 \mathrm{kPa}$. The heavy metals concentration in the sediment extracted by an acidification, digestion process and dilution, are analyzed by Inductively Coupled Plasma-Atomic Emission Spectrometry (ICP-AES).

\section{Results}

\subsection{Dewatering and compressibility efficiency}

The residual water content within the sediment is deduced from effluent volume which accumulates according to time duration. The dewatering is fast during the first hours and is more effective when the potential gradient is higher. After 48 hours testing, the average residual water content in the sludge under a $1.5 \mathrm{~V} / \mathrm{cm}$ potential gradient decreases from $100 \%$ to $67 \%$. However, when the potential gradient is low, the effect of EDW is not obvious (Figure 2).

The effect of an electric potential gradient on moisture distribution after dewatering test is stronger than that of consolidation pressure. It is also shown an increase of residual water from the anode to the cathode. That means that the dewatering of the sludge at anode is more effective than at cathode (electro-osmotic dewatering (EOD) is directed to cathode). Figure 3 shows the influence of electric potential gradient and consolidation pressure on compressibility which had a strong growth at the beginning of the tests and then before decreasing until remaining negligible. 
That means that the dewatering of the sludge at anode is more effective than at cathode (electro-osmotic dewatering (EOD) is directed to cathode). Figure 3 shows the influence of electric potential gradient and consolidation pressure on compressibility which had a strong growth at the beginning of the tests and then before decreasing until remaining negligible. So, when applying high electric voltage gradient $(1.5 \mathrm{~V} / \mathrm{cm})$ a saturation of the compressibility process rises rapidly (within less than a day), indicating that EK effect reaches its maximum effect. When evaluating final dewatering and compressibility efficiency, we can deduce that more higher is the consolidation pressure, more important is the reached compressibility.

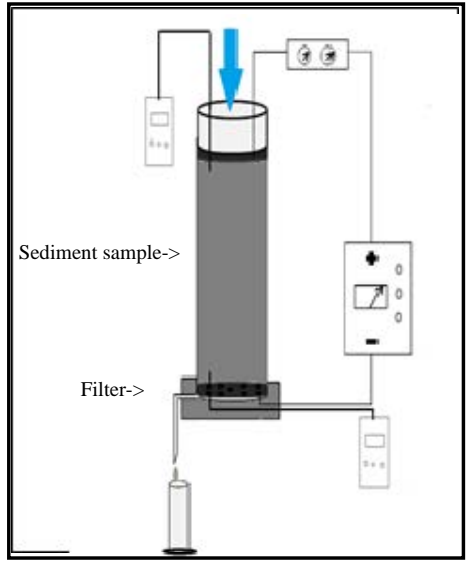

Fig. 1. Experimental set up.

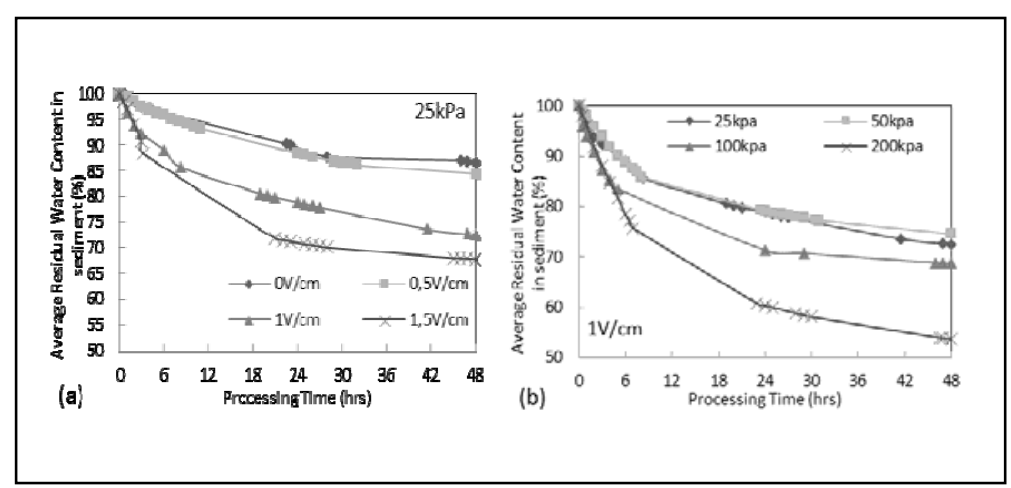

Figure 2. Evolution of residual water content ratio in the sediment during treatment for various conditions

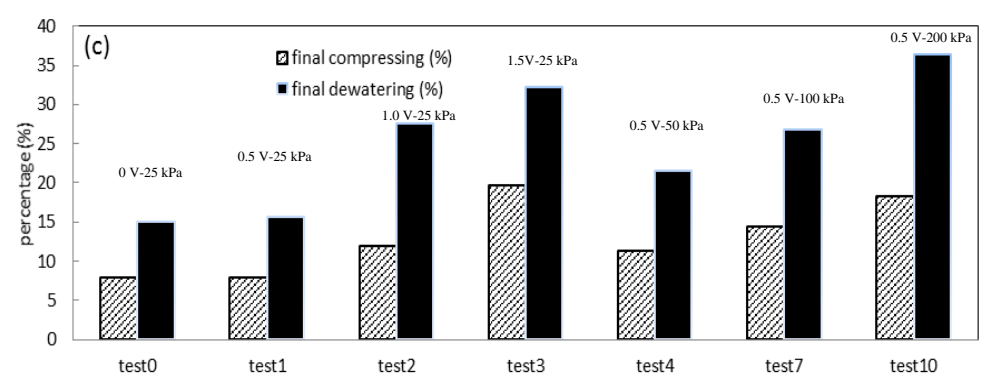

Figure 3. Comparison between final dewatering and compressibility efficiency.

\subsection{Heavy metals removal and energy consumption}

The results (Fig. 4) show that many of targeted contaminants $(\mathrm{Cr}, \mathrm{Pb})$ can be extracted by the EDW process. When the potential gradient is low $(0-0.5 \mathrm{~V} / \mathrm{cm})$, metal contaminants were quite not recovered in the effluent. However, more contaminants can be extracted using a high electric potential gradient. Decontamination capacity of EDW is also depending on the type of metals and voltage gradient level. When high voltage is applied Zn and Cd are difficult to be extracted, while Cr was the easiest contaminant to be extracted from the dredged sediment. As regards to the energetic efficiency of the process, water removal efficiency increases with increase of energy consumption along the processing time (Fig. 5). The optimal processing time can also be deduced, which is 
Côtes méditerranéennes menacées :

Risques et défis dans le contexte du changement climatique

close to $10 \mathrm{hrs}$, involving an energy ratio of $200 \mathrm{kWh} / \mathrm{m}^{3}$. At the end of the test, steady states rise for whole energy consumption and water removal efficiency.

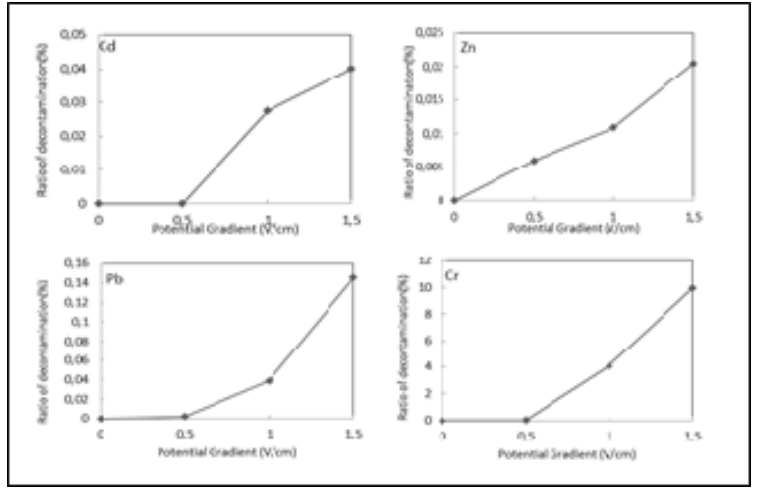

Fig. 4. Removal efficiency of four metals.

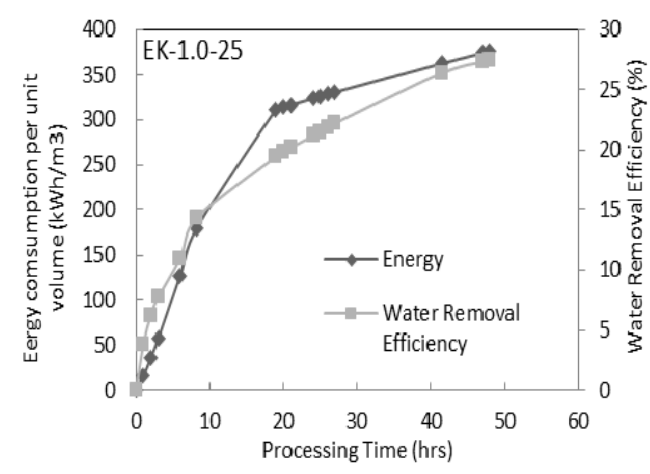

Fig. 5. Energy efficiency of the process.

\section{Conclusions}

This study shows that coupling EDW with MDW can lead to water removal and metals decontamination of dredged sediment, the most efficient process being dewatering. The effect of an electric potential gradient on moisture distribution after dewatering is stronger than that of consolidation pressure and results show that final dewatering is proportional to final compressibility. In general, more water removal efficiency needs more energy consumption, but for same used energy, the water removal efficiency is more important for a lower consolidation pressure. Decontamination capacity of EDW depends on targeted metals and voltage gradient level. $\mathrm{Zn}$ and $\mathrm{Cd}$ are difficult to be extracted while $\mathrm{Cr}$ is the easiest contaminant to be removed.

\section{References}

MAHMOUD A., OLIVIER J., VAXELAIRE J., HOADLEY A. F. (2011). Electrodewatering of wastewater sludge: influence of the operating conditions and their interactions effects. Water Research, Vol. 45(9), pp 2795-810. http://dx.doi.org/10.1016/j.watres.2011.02.029

IWATA M., JAMI M. S., SATO M. (2007). Analysis of constant-current electroosmotic dewatering of various solid-liquid systems by considering the creep deformation. Separation and Purification Technology, Vol. 58(2), pp 274-281. http://dx.doi.org/10.1016/j.seppur.2007.03.017

TUAN P.A., SILLANPAA M. (2010). Effect of freeze/thaw conditions, polyelectrolyte addition, and sludge loading on sludge electro-dewatering process. Chemical Engineering Journal, Vol. 164(1), pp 85-91. http://dx.doi.org/10.1016/j.cej.2010.08.028

YUAN C., WENG C. (2003). Sludge dewatering by electrokinetic technique : effect of processing time and potential gradient. Advances in Environmental Research, Vol. 7, pp 727-732. http://dx.doi.org/10.1016/s1093-0191(02)00030-8 